\title{
TRANSPARENT ZnO-BASED OHMIC CONTACT TO p-GaN
}

\author{
E. Kaminska ${ }^{1}$, A. Piotrowska ${ }^{1}$, K. Golaszewska ${ }^{1}$, M. Guziewicz ${ }^{1}$, R. Kruszka ${ }^{1}$, A. Kudla ${ }^{1}$, \\ T. Ochalski ${ }^{1}$, A. Barcz ${ }^{1,2}$, T. Dietl ${ }^{2}$, F. Matsukura ${ }^{2,3}$, M. Sawicki ${ }^{2}$, A. Wawro ${ }^{2}$, M. Zielinski ${ }^{2}$, \\ J. Jasinski ${ }^{4}$, Z. Liliental-Weber ${ }^{4}$ \\ ${ }^{1}$ Institute of Electron Technology, Al. Lotnikow 46, 02-668 Warsaw, Poland \\ ${ }^{2}$ Institute of Physics, PAS, Al. Lotnikow 46, 02-668 Warsaw, Poland \\ ${ }^{3}$ Research Institute of Electrical Communication, Tohuku University, Sendai 980-8577, Japan \\ ${ }^{4}$ Lawrence Berkeley National Laboratory, Berkeley, CA 94720, U.S.A.
}

\begin{abstract}
Highly conductive $\mathrm{ZnO}$ films were fabricated on $\mathrm{p}-\mathrm{GaN}$ in a two-step process. First, zinc was thermally evaporated on $\mathrm{p}-\mathrm{GaN}$. Next, zinc film was oxidized in oxygen flow. To increase the conductivity of $\mathrm{ZnO}$, nitrogen was introduced into zinc during its deposition. The above procedure proved successful in fabricating $\mathrm{ZnO}$ of the resistivity of $\sim 1 \times 10^{-3} \Omega \mathrm{cm}$ and resulted in ohmic contacts of resistivity $\sim 1 \times 10^{-2} \Omega \mathrm{cm}^{2}$ to low-doped p-GaN, and light transmittance of $\sim 75 \%$ in the wavelength range of $400-700 \mathrm{~nm}$.
\end{abstract}

\section{INTRODUCTION}

In a variety of optoelectronic applications, such as light-emitting, -detecting and -triggered semiconductor devices the top electrode serves as both ohmic contact and optical window. For GaN-based photonic devices, where the major losses of performance are due to poor conductivity of p-type subcontact region, causing the so-called "current crowding" problem, a highly conductive and transparent p-type electrode is a prerequisite. Among the investigated metallizations that would allow low-resistivity contact to $\mathrm{p}-\mathrm{GaN}$, oxidized $\mathrm{Ni} / \mathrm{Au}$ bilayer was reported to give the lowest operating voltages [1-3]. For the transparent p-type electrode, optimization of $\mathrm{Ni} / \mathrm{Au}$ metallization via reducing its thickness [4,5] has been achieved, however, at the cost of increase of the specific contact resistance. Another approach for obtaining effective current-spreading layer, providing low-resistivity contact to p-type $\mathrm{GaN}$ in conjunction with efficient and uniform light emission, would be to make the p-type contact/window layer from a transparent conducting oxide (TCO). Following this approach, indium tin oxide (ITO) films have been recently tested as electrical contacts to p-side of GaN-based light emitting diode (LED), vertical cavity laser (VCSEL) and resonant cavity LED, allowing satisfactory lateral current spreading and required transparency [6,7]. Below, we report on the use of $\mathrm{ZnO}$ as an ohmic contact to p-GaN. This material is an excellent candidate for a thermally stable heterojunction contact to $\mathrm{p}-\mathrm{GaN}$. Both materials posses the same wurtzite structure with small lattice mismatch. As compared to ITO, $\mathrm{ZnO}$ offers higher chemical stability at higher temperatures $[8,9]$. The transport properties of $\mathrm{ZnO}$ depend strongly upon the stoichiometry and on the nature and concentration of impurities and dopants introduced into the film [9]. Usually, $\mathrm{ZnO}$ films are fabricated by sputtering [10] or pulsed laser-deposition [8,9]. New idea of this work is to form highly conductive $\mathrm{ZnO}$ films in a two-step process: first, thin film of elemental $\mathrm{Zn}$ is deposited on $\mathrm{p}-\mathrm{GaN}$ substrate by thermal evaporation in high vacuum. Next, $\mathrm{Zn}$ film is oxidized in an oxygen flow. To increase the doping level, a controlled amount of dopant was introduced into $\mathrm{Zn}$ during its deposition. 


\section{EXPERIMENTAL DETAILS}

The substrate materials for this study were $2 \mu \mathrm{m}$ thick either $\mathrm{Mg}$ doped $\mathrm{p}-\mathrm{GaN}$ $\left(\mathrm{p}=1 \times 10^{17} \mathrm{~cm}^{-3}\right)$ or undoped $\mathrm{GaN}$ epilayers, grown by MOCVD on sapphire. For optical measurements double-side polished sapphire substrates were employed.

During the deposition of $\mathrm{Zn}$, nitrogen as a dopant species was bled into vacuum chamber by means of a regulated valve, at a partial pressure from the range $1 \times 10^{-4}-4 \times 10^{-6}$ Torr. To promote uniform condensation of $\mathrm{Zn}$ on non-metallic substrates, an Au nucleation film was predeposited. $\mathrm{Zn}$ films of a thickness 50-100 nm were used in our experiments. The oxidation of $\mathrm{Zn}$ was carried out by furnace annealing in $\mathrm{O}_{2}$ flow, at $300-320^{\circ} \mathrm{C}$, i.e. $20-40^{\circ} \mathrm{C}$ below the sublimation temperature of $\mathrm{Zn}$ [11]. Finally, $200 \mathrm{~nm}$ thick Au or Pt overlayer for contacting purposes was deposited, and samples were patterned for electrical measurements. In order to avoid the incorporation of uncontrolled impurities, only high purity materials $(99,999 \%)$ were used in fabrication of $\mathrm{ZnO}$ films.

The transport properties of thin $\mathrm{ZnO}$ films were assessed from measurements of sheet resistance by four-point probe, and using van der Pauw method. Ohmic contacts were characterized by circular transmission line method (CTLM) [12]. The dimensions, in notation [12], were: $\mathrm{r}_{0}=30 \mu \mathrm{m}, \mathrm{r}_{1}{ }^{\prime}=54 \mu \mathrm{m}, \mathrm{r}_{1}=85 \mu \mathrm{m}, \mathrm{r}_{2}{ }^{\prime}=138 \mu \mathrm{m}, \mathrm{r}_{2}=174 \mu \mathrm{m}$. Measurements were carried out using Keithley 2400 SourceMeter. Optical transmission of the films was measured by means of monochromatically dispersed light of quartz-tungsten-halogen lamp. Intensity of transited light was detected by using Si photodiode biased in reversed polarization. Optical parameters of the $\mathrm{ZnO}$ layers were determined with Woollam VASE spectroscopic ellipsometer. Measurements were done at two angles $65^{\circ}$ and $75^{\circ}$. The surface morphology of $\mathrm{ZnO}$ films was characterized by atomic force microscopy (AFM). The microstructure of contacts was investigated by cross-sectional transmission electron microscopy (XTEM) and high resolution imaging (HREM) combined with energy dispersive x-ray spectroscopy (EDX). TEM observations were performed using a Topcon 002B microscope operating at $200 \mathrm{keV}$. EDX studies were done using Philips CM200 microscope. A microprobe size of $1.4 \mathrm{~nm}$ was used for EDX analysis. Fast Fourier transform (FFT) of HREM images were used to identify crystalline phases. SIMS profiling was performed with a Cameca $6 \mathrm{~F}$ instrument with a cesium primary ion beam and detection of $\mathrm{CsMi}+$ secondary cluster ions.

\section{RESULTS AND DISCUSSION}

\section{Electrical properties}

Resistivity of oxidized zinc films as a function of the partial pressure of $\mathrm{N}_{2}$ during zinc deposition is plotted in figure 1(a). While the nominally undoped $\mathrm{ZnO}$ films were highly resistive, by introducing nitrogen into the deposition chamber it was possible to decrease the resistivity down to $1 \times 10^{-3} \Omega \mathrm{cm}$. Hall effect measurement performed on low-resistivity samples showed that the material is n-type and degenerately doped. The thickness of oxidized zinc films was $\sim 1.2$ times higher as compared to the as-deposited ones. The typical I-V characteristic of $\mathrm{p}-\mathrm{GaN} / \mathrm{ZnO} / \mathrm{Au}$ contact is shown in figure 1(b). As-deposited contacts exhibited linear I-V behavior. The resistivity of contacts formed on low-doped p-type $\mathrm{GaN}\left(\mathrm{p}=1 \times 10^{17} \mathrm{~cm}^{-3}\right)$ was 1$2 \times 10^{-2} \Omega \mathrm{cm}^{2}$. 

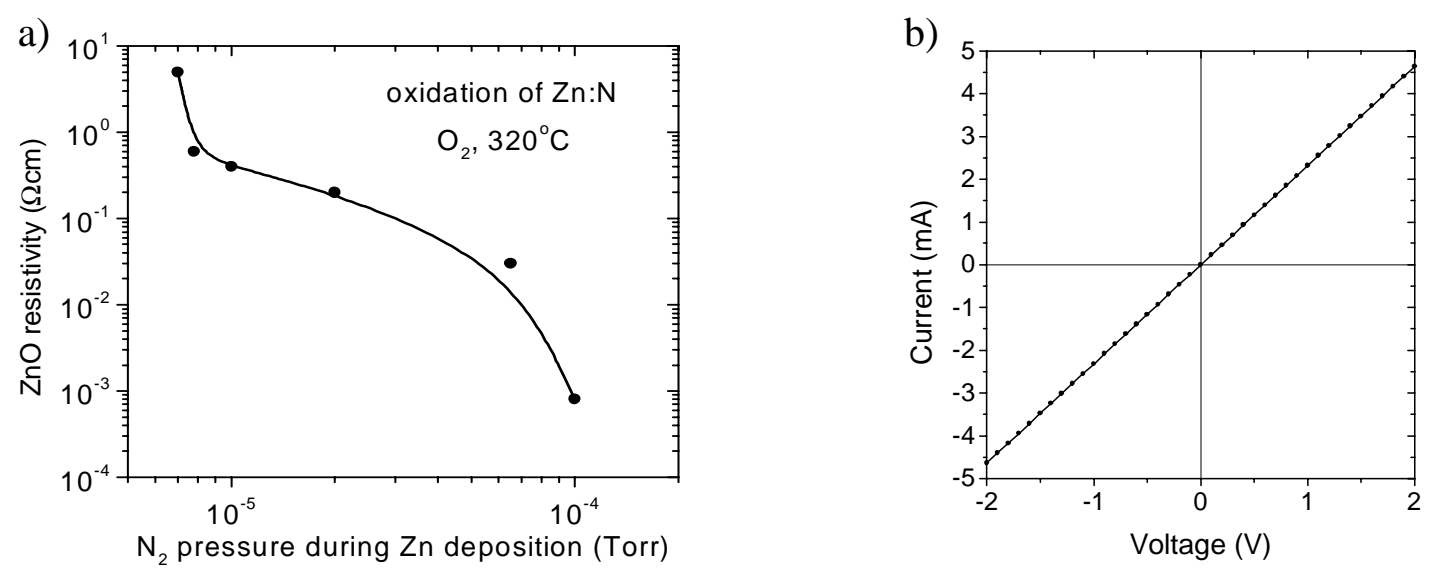

Figure 1. (a) Resistivity of $\mathrm{ZnO}$ as a function of $\mathrm{N}_{2}$ partial pressure during the deposition of $\mathrm{Zn}$ and (b) I-V characteristic of the as-deposited $\mathrm{p}-\mathrm{GaN} / \mathrm{ZnO} / \mathrm{Au}$ contact.

\section{Optical properties}

In figure 2 are presented refraction $\mathbf{n}$ and extinction $\mathbf{k}$ indices as a function of wavelength in 240-1100 nm spectral range. $120 \mathrm{~nm}$ thick $\mathrm{ZnO}$ films show an average transmission of about $75 \%$ for wavelengths between 400 and $700 \mathrm{~nm}$, as given in figure 3 .

\section{Contact microstructure}

As analyzed by AFM, nuclei of gold form at the surface of GaN regularly shaped grains, $\sim 5$ $\mathrm{nm}$ in size. Deposition of zinc resulted in the RMS roughness of $7.35 \mathrm{~nm}$. The size of zinc grains was 40-50 nm. Upon oxidation grains slightly grew, and the surface roughened up to $11.3 \mathrm{~nm}$. The surface morphology of oxidized zinc film on $\mathrm{GaN}$ is presented in figure 4.

Figures 5(a) and (b) are SIMS profiles showing the elemental composition of the uniformly oxidized zinc films on $\mathrm{GaN}$ and sapphire substrates. Although the presence of nitrogen can be inferred from the step in the profile occurring within the $\mathrm{ZnO}$ film deposited on $\mathrm{GaN}$, the signal is partially masked by the $\mathrm{N}$ contribution from the semiconductor. Therefore, similar metallization was prepared on a sapphire substrate where the $\mathrm{N}$ content is clearly seen.

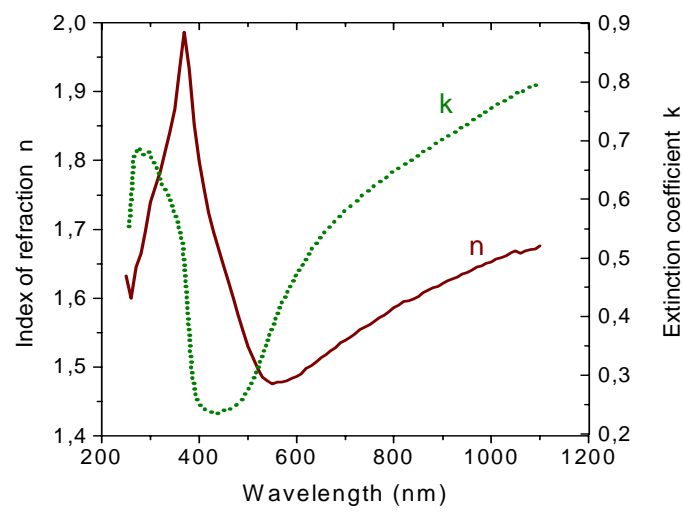

Figure 2. Refraction and extinction indices of $\mathrm{ZnO}$.

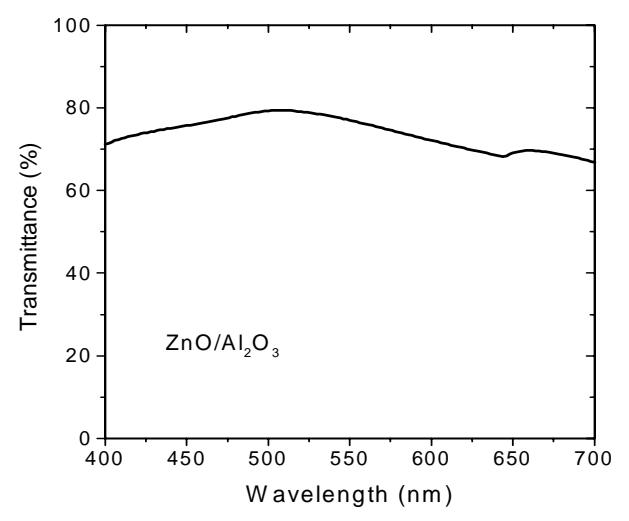

Figure 3. Transmittance of $\mathrm{ZnO}$ film as a function of wavelength. 


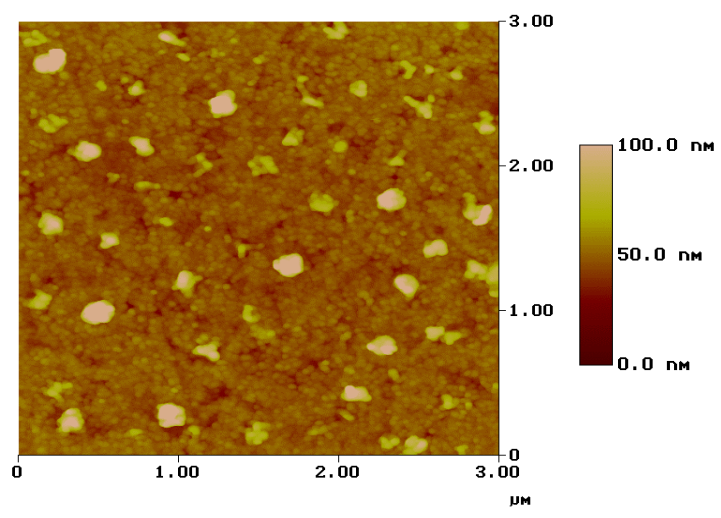

Figure 4. AFM image of the surface of oxidized Zn film.

The microstructure of the as-deposited GaN/Zn contact, shown in figure 6(a), consists of two distinct films. As inferred from EDX analysis, the first, interfacial one, is composed of $\mathrm{Au}$ and $\mathrm{Zn}$, the second being $\mathrm{Zn}$. TEM analysis of the GaN/oxidized zinc interface, given in figure 6(b), shows an intact initial surface of $\mathrm{GaN}$, adjacent to which elongated (20-40 nm) grains are visible. These are embedded in a continuous overlayer. High resolution analysis assisted by fast Fourier transform procedure (FFT), performed on the above described distinct areas, made it possible to identify the islands as gold, and the main layer as crystalline zinc oxide. HREM images and corresponding FFTs are presented in figure 6(c).

\section{CONCLUSIONS}

We have successfully developed a fabrication method of high conductivity, transparent zinc oxide and have applied it to manufacturing of a transparent ohmic contact to p-type GaN. It was found that electrical properties $\mathrm{ZnO}$ thin films, formed by thermal evaporation of zinc and consecutive zinc oxidation, could be precisely controlled by varying the partial pressure of nitrogen, introduced into the zinc deposition chamber.

a)

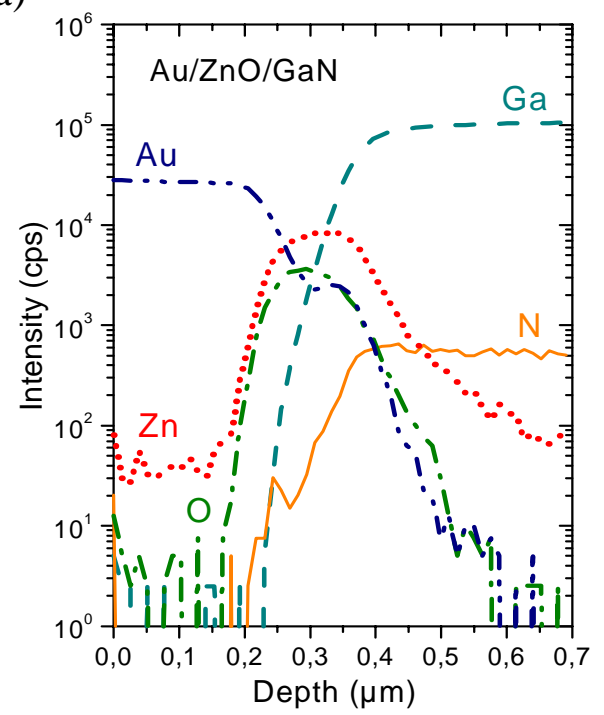

b)

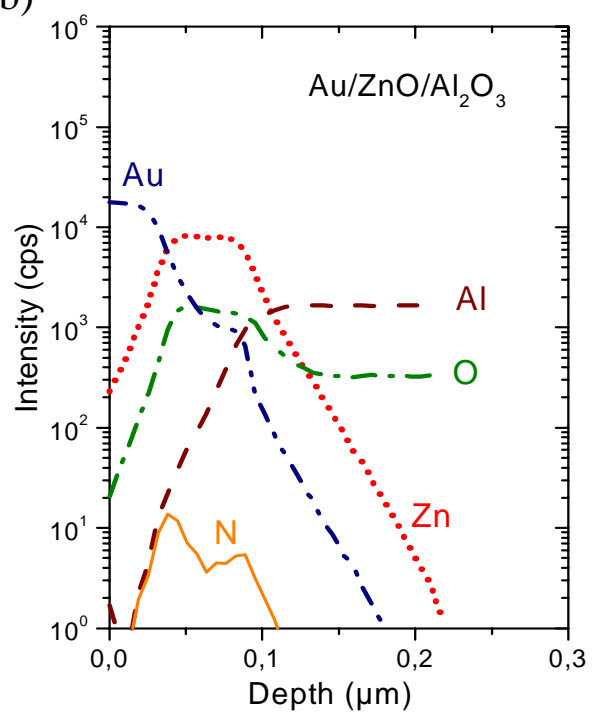

Figure 5. SIMS profiles of $\mathrm{ZnO} / \mathrm{Au}$ contacts manufactured on (a) $\mathrm{GaN}$ or (b) sapphire substrates. 
a)

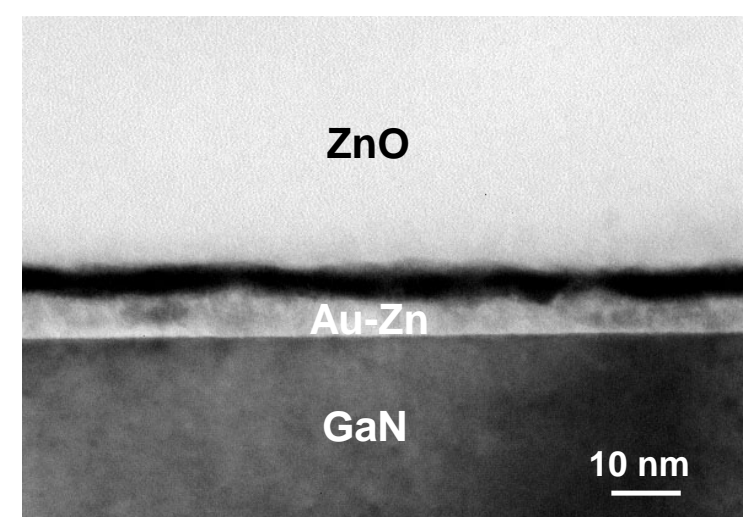

b)

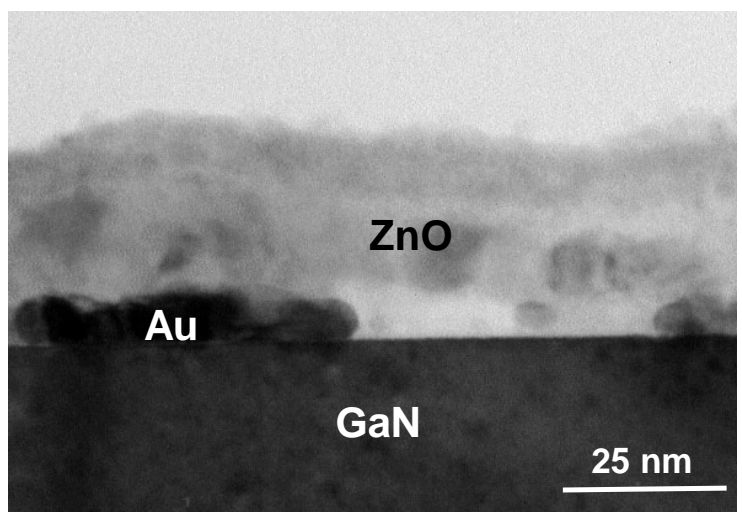

c)

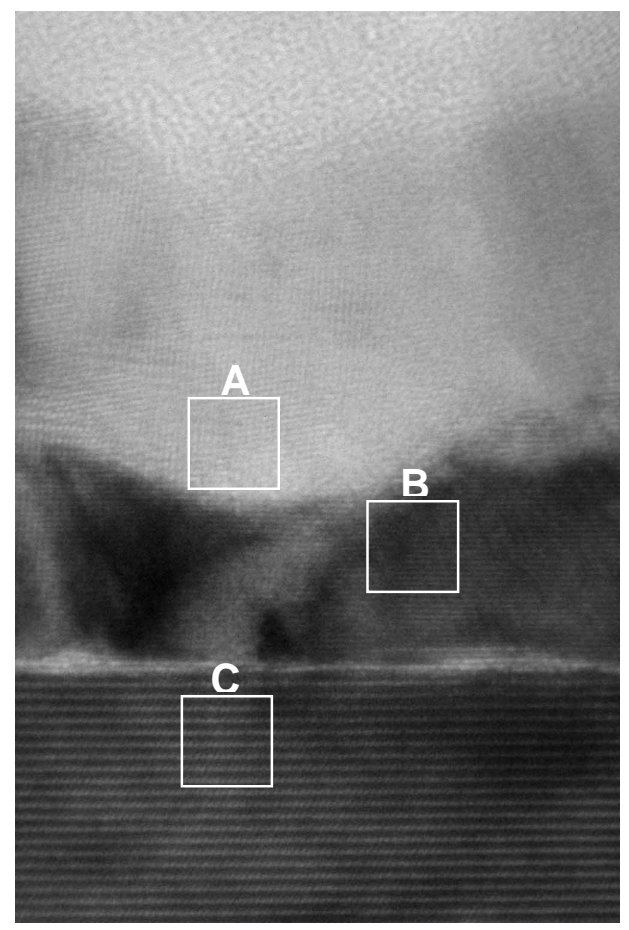

HREM
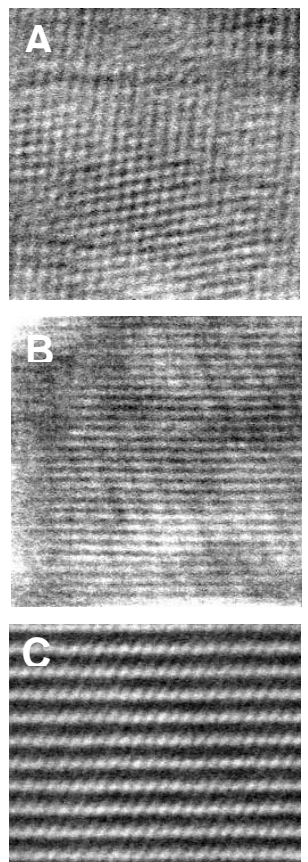

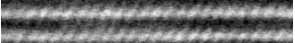

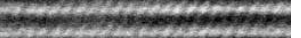

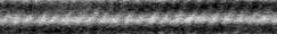

FFT
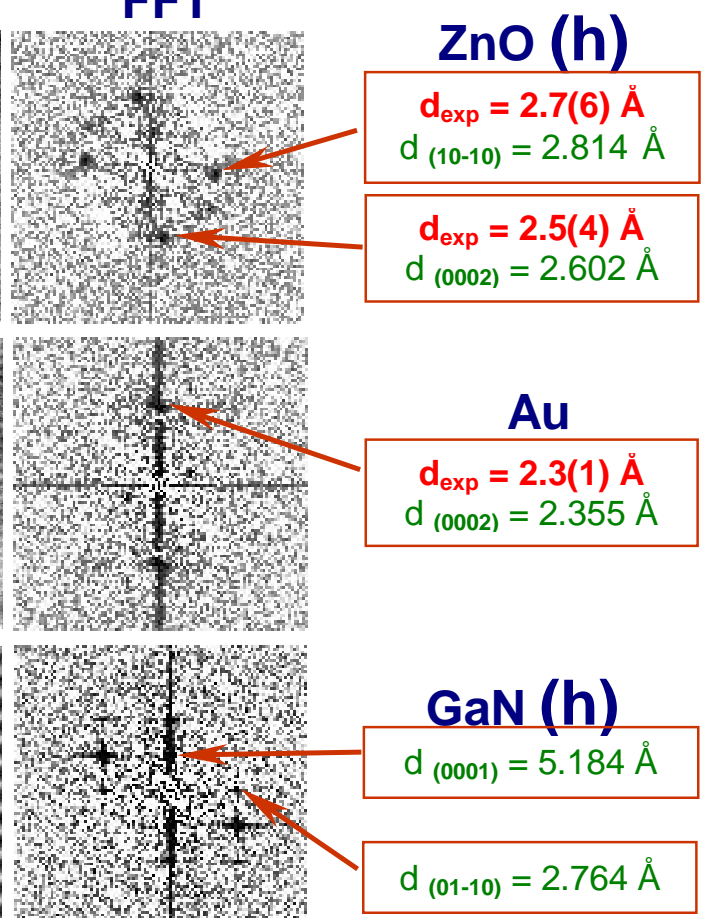

Figure 6. TEM micrographs of GaN/Zn interface: (a) as-deposited, (b) after oxidation, (c) highresolution images of crystalline phases in oxidized contact and corresponding FFTs.

The optical transmission $\sim 75 \%$ was measured on $120 \mathrm{~nm}$ thick $\mathrm{ZnO}$ films. For comparison, to yield the same transmission, the Ni/Au metallization had to be thinned down to $\sim 15 \mathrm{~nm}$ [5], while $\sim 80 \%$ transmission was reported for $25 \mathrm{~nm}$ thick ITO contacts [6].

The study of the microstructure of $\mathrm{GaN} / \mathrm{ZnO}$ contact shows two distinct phases at the contact interface, namely $\mathrm{Au}$ and $\mathrm{ZnO}$. Since Au does not provide ohmic contact to low-doped ptype $\mathrm{GaN}$, the observed ohmic behavior may be attributed to the formation of $\mathrm{n}^{+}-\mathrm{ZnO}$. We note 
that ohmic characteristics are obtained without any reaction at the metal-semiconductor interface. This in turn implies a lowering of the barrier height at the contact interface. The work function of $\mathrm{ZnO}$ is about $5 \mathrm{eV}$ [10], but in view of results reported recently by Klein for degenerately doped $\mathrm{In}_{2} \mathrm{O}_{3}$ thin films [13], we can expect the formation of a depletion layer in the superficial region of highly doped $\mathrm{ZnO}$. The resultant band bending at the $\mathrm{p}-\mathrm{GaN} / \mathrm{n}^{+}-\mathrm{ZnO}$ interface in conjunction with high bulk conductivity of $\mathrm{ZnO}$ would explain the ohmic properties of this interface.

We expect that the presented ohmic contact technology might be further improved by optimization of the deposition procedure of the nucleation film.

\section{ACKNOWLEDGMENTS}

Research is partially supported by grants from European Commission IST-199-10292AGETHA and the Committee for Scientific Research 7T11B 009 20. TEM group (J.J. and Z. L.-W.) supported by the Director, Office of Science, Office of Basic Energy Sciences, Division of Materials Sciences, of the U.S. Department of Energy under Contract No. DE-AC0376SF00098 wants to thank W. Swider for TEM sample preparation, and the NCEM in Berkeley for use of the TEM facility.

\section{REFERENCES}

1. J.-K. Ho, C.-S. Jong, C.C. Chiu, C.-N. Huang, K.-K. Shih, L.C. Chen, F.R. Chen, and J.-J. Kai, J. Appl. Phys. 86, 4491 (1999).

2. N. Shibata, J. Umezaki, M. Arai, T. Uemura, T. Kozawa, T. Mori and T. Owaki, Japanese Unexamined Patent No 09064337A.

3. J.-K. Ho, C.-S. Jong, C.C. Chiu, C.-N. Huang, C.-Y. Chen and K.-K. Shih, Appl. Phys. Lett. 74, 1275 (1999).

4. J.K. Sheu, Y.K. Su, G.C. Chi, P.L. Koh, M.J. Jou, C.M. Chang, C.C. Liu and W.C. Hung, Appl. Phys. Lett. 74, 2340 (1999).

5. J.-S. Jang, S.-J. Park and T.-S. Seong, J. Appl. Phys. 88, 5490 (2000).

6. T. Margalith, O. Buchinsky, D. A. Cohen, A. C. Abare, M. Hansen, S. P. DenBaars and L.A. Coldren, Appl. Phys. Lett. 74, 3930 (1999).

7. Y.-K. Song, M. Diagne, H. Zhou, A. V. Nurmikko, R. P. Schneider, Jr., Phys. Stat. Sol. (a) 180, 33 (2000).

8. Y.R. Ryu, S. Zhu, J. D. Budai, H. R. Chandrasekhar, P. F. Micelli and H. W. White, J. Appl. Phys. 88, 201 (2000).

9. S. B. Qadri, H. Kim, H. R. Khan, A. Pique, J. S. Horowitz, D. Chrisey, W. J. Kim, E. F. Skelton, Thin Solid Films 377-378, 750 (2000).

10. T. Minami, T. Miyata, T. Yamamoto, Surface and Coating Technol. 108-109, 583, (1998).

11. Handbook of Thin Film Technology, eds. L.I. Maissel, R. Glang, McGrow-Hill Book Company, (N.Y. 1970).

12. G. K. Reeves, Solid State Electronics, 23, 487 (1980).

13. A. Klein, Appl. Phys. Lett. 77, 2009 (2000). 